\title{
Extracranial metastases from a glioma in the absence of surgical intervention
}

\author{
W. L. BRANDER AND D. R. TURNER \\ From the Department of Histopathology, Guy's Hospital Medical School, London
}

SYNOPSIS A case of metastatic spread to the pleura from a glioma which had not been biopsied or treated surgically is reported. There was no direct extension to extracranial soft tissues, the route of spread apparently being by way of meningeal veins.

Metastases from intracranial tumours, and gliomas in particular, to remote parts of the body are rare (Russell and Rubinstein, 1963). Indeed, Bailey and Cushing (1926) could find no evidence that it ever occurred. Later reports show that it does happen, but only after operative interference with the tumour. In most cases there has been evidence of infiltration of extracranial tissues at the operation site, though Rubinstein (1959) described a case of metastasis after direct extension of a medulloblastoma to the soft tissues of the orbit.

Weiss (1955) set out four criteria which should apply before a case of metastasizing central nervous system tumour is accepted. (1) The presence of a single, histologically characteristic tumour of the central nervous system must have been proved. (2) The clinical history must indicate that the initial symptoms were due to this tumour. (3) A complete necropsy must have been performed and reported in sufficient detail to rule out the possibility of any other primary site. (4) The morphological appearance of the tumour of the central nervous system and the distant metastases must have been identical, with due allowance of differences in degree of anaplasia.

The case presented below satisfies these criteria, but was not subject to surgical intervention, or infiltration of extracranial soft tissues. The route of spread by way of meningeal veins is a phenomenon not previously described.

\section{CASE REPORT}

Mrs B.B., aged 30 years, presented with a history of (Accepted 30 June 1975.) clumsiness of her right hand for about two years, and the more recent onset of transient bouts of blindness and recurrent severe generalized headaches. Examination showed sensory loss affecting

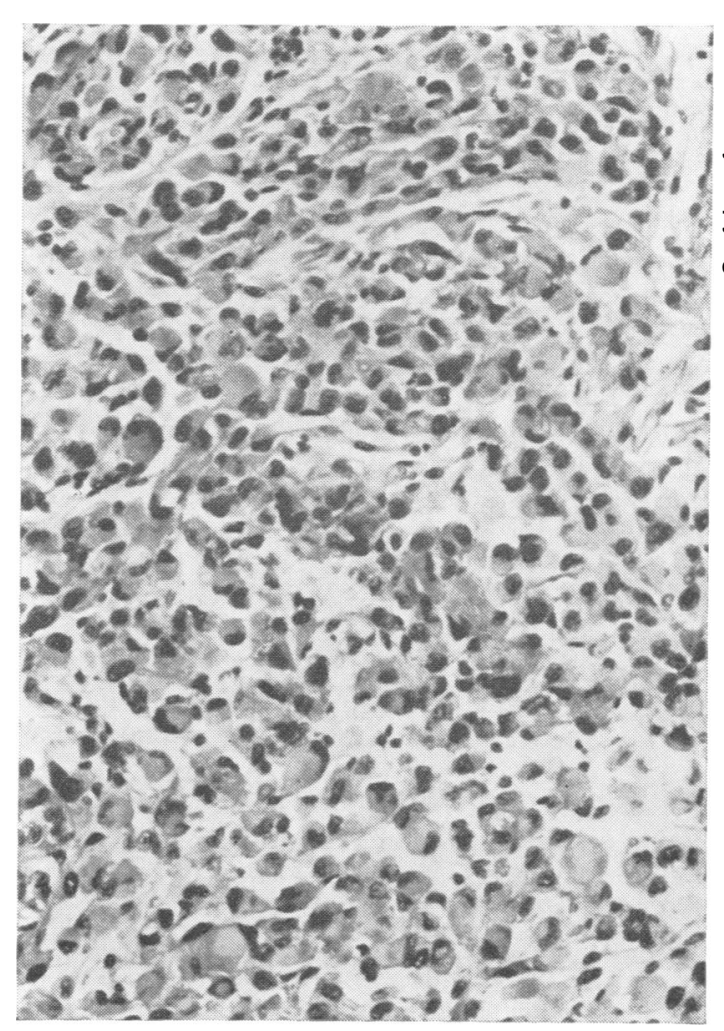

FIG. 1 A pleomorphic gemistocytic area of the primary tumour. $H$ and $E, \times 100$. 


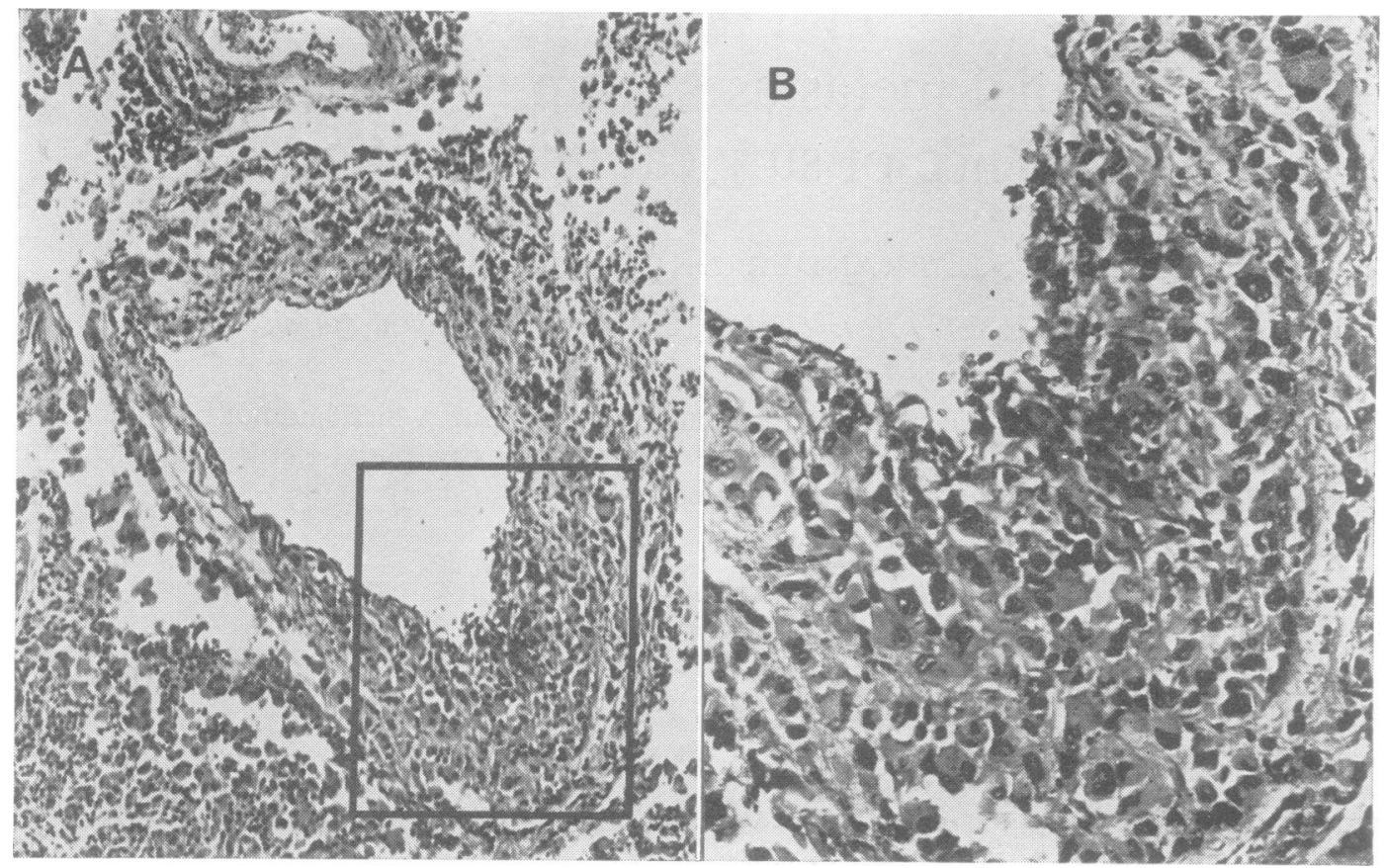

FIG. 2 A. Low power view of meningeal vein infiltrated by tumour cells. $H$ and $E, \times 40 . \mathrm{B}$. Close up of marked area. $H$ and $E, \times 100$.

the right arm and leg, and a right homonymous hemianopia. Carotid arteriograms showed a deep seated, left sided, parieto-occipital space-occupying lesion. It was considered not to be amenable to surgical treatment and biopsy was not undertaken.

Her symptoms and signs progressed very gradually during the next four years, with weakness as well as sensory loss. Carotid arteriography was repeated confirming the presence of the tumour in the left thalamus. At this time, it showed scattered foci of calcification and was considered to be an oligodendroglioma, but it was not biopsied.

Twelve years after presenting, the weakness began to affect her face and tongue as well as her right arm and leg. She was treated with a total of 4,000 rads of mega-voltage radiotherapy by the Cobalt 60 unit with some benefit. She now had papilloedema and was treated with dexamethasone. Her condition remained little changed for the next year, but she was then readmitted with malaise, vomiting, and headache. She rapidly lapsed into coma and died 13 years after presentation and 14 months after radiotherapy, never having had surgical treatment or biopsy of her tumour.

POSTMORTEM EXAMINATION The brain weighed 1,505 $\mathrm{g}$ and was oedematous. There was a single illdefined tumour mass centred in the left thalamus extending down through the mid brain and pons to become adherent to the dura mater over the posterior surface of the petrous temporal bone. The dura mater and bone were not infiltrated, nor was there extension to the internal auditory meatus.

There were numerous tumour deposits up to 10 $\mathrm{mm}$ in diameter in both the visceral and parietal pleura of the right lung. An exhaustive examination revealed no other tumour.

MICROSCOPY The cerebral tumour proved to be a malignant glioma with a variety of patterns. In places it resembled an oligodendroglioma, in places a small-celled astrocytoma, and in others a gemistocytic astrocytoma with giant cell and anaplastic variants (Fig. 1). In one of the sections it could be seen infiltrating the wall of a meningeal vein (Fig. 2). The tumour deposits in the pleura were identical with parts of the cerebral lesion (Fig. 3).

\section{DISCUSSION}

This case satisfies the criteria of Weiss (1955) and 


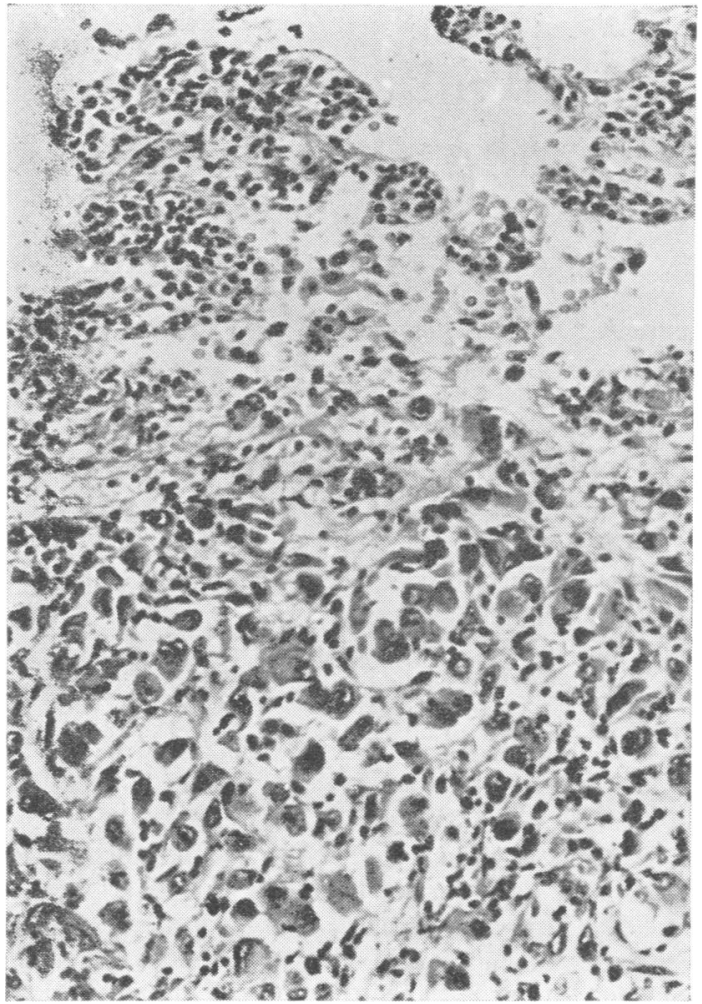

FIG. 3 A pleural deposit involving the lung parenchyma. $H$ and $E, \times 100$.

so qualifies as an example of remotely metastasizing glioma. It differs from the previous reports in that there was no surgical assault on the tumour, nor was there direct extension to extracranial soft tissues by infiltration through the skull. The literature on metastasizing central nervous system tumours has been reviewed by Willis (1973), who points out that neoplastic invasion of vascular channels is rarely if ever seen in sections of cerebral tumours. In this case, infiltration of meningeal veins appears to have been the mode of spread. Why the pleura was the site of the metastases remains an enigma.

Perry (1957) pointed out that the common factors in cases of remote metastases from cerebral tumours were; (1) multiple operations, (2) radiation, and (3) prolonged survival. Only the latter two apply in this case. Russell and Rubinstein (1963) state that, in general, malignant changes are to be anticipated in cerebral astrocytoma, but that the timing is unpredictable. Presumably, prolonged survival increases the chance of this happening in a particular case, thereby enhancing the infiltrative capacity of the tumour. On the other hand, it remains a matter for conjecture what part, if any, the radiotherapy played in the dedifferentiation and metastatic spread of this tumour.

We are indebted to Dr M. J. F. McArdle for permission $\frac{0}{0} \overrightarrow{\vec{\omega}}$ to publish this case. We would like to thank Dr R. O. $\vec{\Phi} \omega$ Weller (consultant neuropathologist and senior lecturer $\stackrel{9}{\stackrel{9}{1}}$ 윽 in pathology at Southampton General Hospital) and $\stackrel{D}{\varrho}-$ Professor C. W. M. Adams (Guy's Hospital) who independently confirmed our view that this is a genuine case of metastasizing glioma.

\section{REFERENCES}

Bailey, P., and Cushing, H. (1926). A Classification of Tumors of the Glioma Group. Lippincott: Philadelphia.

Perry, R. E. (1957). Extracranial metastasis in a case of intracranial ependymoma. Archives of Pathology, 64, 337-341.

Rubinstein, L. J. (1959). Extracranial metastases in cerebellar medulloblastoma. Journal of Pathology, 78, 187-195.

Russell, D. S., and Rubinstein, L. J. (1963). Pathology of Tumours of the Nervous System, 2nd edn. Arnold: London.

Weiss, L. (1955). A metastasising ependymoma of the cauda equina. Cancer, 8, 161-171.

Willis, R. A. (1973). The Spread of Tumours in the Human Body, p. 101. Butterworths: London. 